\title{
PENGEMBANGAN PTS BERBASIS TEMA MELALUI BIMBINGAN KELOMPOK JARI DIVA
}

\author{
Zainal \\ Pengawas SD Kota Singkawang \\ Email:zainal_mra@yahoo.co.id
}

\begin{abstract}
Abstrak
Permasalahan pelaksanaan Penilaian Tengah Semester (PTS) yang masih dilaksanakan secara parsial berdasarkan muatan pelajaran oleh guru binaan menunjukkan ketidaksesuaian antara pelaksanaan pembelajaran dengan penilaian yang dilaksanakan. Guru kelas pada sekolah binaan mengalami kesulitan dalam pengembangan soal PTS berbasis tema. Bimbingan kelompok JARI DIVA menjadi alternatif untuk meningkatkan kemampuan guru dalam mengembangkan PTS Berbasis Tema. Bimbingan Kelompok JARI DIVA dilaksanakan sejak semester II tahun pelajaran 2017/2018 hingga semester II tahun pelajaran 2018/2019 terhadap guru kelas 1,2,4, dan 5 pada gugus 13,16, dan 19 Singkawang. Bimbingan kelompok JARI DIVA yang dilaksanakan melalui workshop dilanjutkan kerja mandiri kemudian dilakukan diskusi dan validasi hasil kerja mandiri terbukti dapat meningkatkan kemampuan guru dalam mengembangkan PTS berbasis tema, yang dibuktikan dengan pemenuhan produk kisi-kisi dan soal PTS berbasis tema oleh guru di gugus 19 Singkawang 84\%, Gugus 13 Singkawang 86\%, dan gugus 16 Singkawang $83 \%$.
\end{abstract}

\section{Kata Kunci: Bimbingan Kelompok, JARI DIVA, PTS Berbasis Tema}

\section{PENDAHULUAN}

Penilaian yang dilaksanakan dalam pembelajaran memiliki fungsi yang beragam sesuai dengan aspek yang dinilai dan tujuan dari penilaian yang dilakukan. Hasiati dan Basuki (2012:9) mengatakan bahwa penilaian dalam pembelajaran harus diarahkan pada: (a) keeping track yaitu untuk menelusuri agar proses pembelajaran peserta didik tetap sesuai dengan rencana, (b) checking-up yaitu untuk mengecek kelemahan yang dialami peserta didik dalam pembelajaran, (c) finding-up yaitu untuk mencari dan menentukan hal-hal yang menyebabkan terjadinya kelemahan dan kesalahan dalam proses pembelajaran, (d) summing-up yaitu untuk menyimpulkan ketercapaian kompetensi yang ditentukan oleh peserta didik. Penilaian yang dilaksanakan dalam proses dan hasil belajar harus mampu mencerminkan secara komprehensif mengenai kompetensi peserta didik yang diperoleh melalui pembelajaran. Terkait itu, penilaian harus dilakukan secara holistik meliputi aspek sikap, pengetahuan dan keterampilan baik selama proses pembelajaran berlangsung (penilaian proses) maupun setelah pembelajaran usai dilaksanakan (penilaian hasil belajar) (Kemdikbud,2013).

Penilaian pembelajaran dilaksanakan secara bertahap mulai dari penilaian harian, tengah semester, akhir semester dan akhir tahun untuk memperoleh informasi kemajuan belajar siswa dalam satuan waktu tertentu. Sesuai panduan penilaian kurikulum 2013, penilaian dapat dibedakan menjadi Penilaian Harian (PH), Penilaian Tengah Semester (PTS), Penilaian Akhir Semester (PAS) dan 
Penilaian Akhir Tahun (PAT) (Kemdikbud,2016:47). Penilaian harian dilaksanakan untuk memperoleh informasi hasil belajar siswa dalam satu atau beberapa pembelajaran. Demikian pula penilaian tengah semester untuk memperoleh informasi hasil belajar siswa setelah mengikuti pembelajaran delapan sampai sembilan minggu atau setelah pembelajaran dua tema.

Penilaian pembelajaran dilaksanakan harus mengacu pada pendekatan pembelajaran yang digunakan, karena itu pelaksanaan PTS untuk kurikulum 2013 dilaksanakan berbasis tema sesuai dengan pendekatan pembelajaran tematik terpadu. Seperti yang dijelaskan dalam penduan penilaian kurikulum 2013 bahwa penilaian tengah semester dilaksanakan setelah pembelajaran Tema 1 dan Tema 2 selesai (untuk kelas I) atau setelah Pembelajaran Tema 1, Tema 2, dan Tema 3 selesai (untuk kelas IV). Selanjutnya dijelaskan pula bahwa "soal-soal tes tertulis dapat juga dibuat terpadu untuk beberapa muatan pelajaran". (Kemdikbud,2016:17). Pernyataan ini berarti penilaian pengetahuan pada tengah semester (PTS), akhir semester (PAS, dan akhir tahun (PAT) dibuat berbasis tema.

Pembelajaran dikelola dengan tematik terpadu berarti penilaian yang dilakukan secara terpadu pula sesuai kompetensi dasar muatan pelajaran yang dipadukan dalam satu pembelajaran. Penilaian pembelajaran yang dilaksanakan baik penilaian harian, tengah semester, akhir semester, maupun akhir tahun harus sesuai dengan pendekatan pembelajaran yang diterapkan. Sebagai contoh penilaian harian untuk kompetensi pengetahuan yang dilakukan pada akhir pembelajaran untuk satu sub tema, maka soal tes yang digunakan mencakup kompetensi dasar dari beberapa muatan pelajaran yang dibelajarkan, demikian pula untuk penilaian tengah semester (PTS), akhir semester (PAS), dan akhir tahun (PAT).

Hasil pengawasan terhadap sekolah binaan sasaran pelaksanaan kurikulum dalam tiga tahun terakhir, penilaian tengah semester (PTS) masih dilaksanakan oleh guru kelas secara parsial berdasarkan muatan pelajaran.
Kondisi ini menunjukkan ketidaksesuaian pola penilaian pembelajaran dengan pengelolaan pembelajaran secara tematik terpadu. Akibatnya, peserta didik yang mengikuti PTS mengalami kesulitan untuk menyiapkan diri mengikuti PTS karena buku materi yang dimiliki peserta didik dikemas dalam satu tema yang didalamnya memuat empat sub tema dan setiap sub tema terdiri dari enam pembelajaran yang terdiri dari beberapa muatan pelajaran. Kesulitan yang dihadapi siswa ketika harus membaca materi yang akan diujikan harus memilah satu muatan pelajaran dalam 24 pelajaran untuk menyiapkan diri dalam PTS untuk satu muatan pelajaran. Keluhan-keluhan tersebut sering disampaikan orang tua peserta didik tentang kesulitan anak-anak mereka ketika mengikuti PTS, PAS dan PAT.

Informasi yang diperoleh pengawas sekolah dari guru kelas pada pelaksanaan kunjungan sekolah binaan, alasan yang dikemukakan guru kelas melaksanakan penilaian pengetahuan berdasarkan muatan pelajaran karena mengalami kesulitan untuk melaksanakannya. Kendala yang dihadapi guru kelas adalah kesulitan dalam mengembangkan soal tes berbasis tema dan kesulitan dalam pengolahan hasil penilaian karena harus memilah berdasarkan kompetensi dasar masing-masing muatan pelajaran. Guru sudah terbiasa mengembangkan soal tes berdasarkan muatan pelajaran tertentu sehingga merasa kesulitan untuk mengembangkan kisi-kisi dan soal tes yang harus menggabungkan beberapa muatan pelajaran dalam satu perangkat tes seperti PTS berbasis tema.

Fakta yang terjadi dalam pelaksanaan PTS di sekolah binaan sebagaimana digambarkan terdahulu perlu segera di atasi agar penilaian yang dilakukan sesuai dengan panduan penilaian yang berlaku dan pendekatan pembelajaran yang diterapkan. Alternatif yang dilakukan pengawas sekolah adalah dengan menerapkan bimbingan kelompok JARI DIVA terhadap guru kelas sasaran pelaksana kurikulum 2013 untuk meningkatkan kemampuan guru dalam mengembangkan PTS berbasis Tema. 
Pembimbingan yang dilakukan pengawas sekolah diarahkan agar guru mampu melaksanakan tugas pokoknya merencanakan, melaksanakan dan menilai pembelajaran serta tugas-tugas tambahan lainnya secara opotimal. Pembimbingan merupakan serangkaian kegiatan yang dilakukan kepala sekolah membantu pendidik mengembangkan kemampuannya dalam mencapai tujuan pembelajaran (Kemdikbud,2012:1).

Pembimbingan yang dilakukan pengawas sekolah dapat dilakukan dalam bentuk individu maupun kelompok. Teknik supervisi terdiri dari dua macam yaitu teknik supervisi individual dan teknik supervisi kelompok (Kemdikbud,2014:5). Apabila permasalahan dialami oleh satu atau dua guru dan kepala sekolah, pengawas melakukan bimbingan individu, tetapi apabila suatu permasalahan dialami beberapa guru atau kepala sekolah berarti harus melakukan bimbingan kelompok. Teknik kelompok diterapkan jika banyak guru mengalami permasalahan yang sama pada mata pelajaran yang sama atau berbeda.(Sahertian dalam Sagala,2012:173). Selanjutnya Rahman, dkk (2016:36) mengatakan bahwa dalam supervisi kelompok, kepala sekolah, guru, atau tenaga kependidikan dikelompokkan berdasarkan masalah atau kebutuhan atau kelemahankelemahan yang sama sesuai hasil analisis kebutuhan. Permasalahan penyusunan PTS berbasis tema dihadapi oleh semua guru di sekolah binaan, karena itu dilakukan pendampingan secara kelompok.

Pelaksanaan bimbingan kelompok memerlukan teknik atau strategi tertentu agar pelaksanaan bimbingan kelompok dapat terlaksana secara efektif. Salah satu teknik bimbingan yang dapat digunakan dalam meningkatkan kemampuan sekelompok guru yang menghadapi permasalahan yang sama adalah bimbingan kelompok. Bimbingan kelompok yang digunakan dalam penulisan ini adalah bimbingan kelompok JARI DIVA. Kelompok diartikan sebagai beberapa atau sejumlah orang yang berada pada tempat yang sama dan memiliki tujuan yang sama. Selanjutnya JARI DIVA adalah gabungan dua akronim yaitu: JARI (Kerja Mandiri) dan DIVA (Diskusi Validasi).

Permasalahan yang dialami guru kelas pada sekolah binaan dalam pelaksanaan PTS dilakukan pembimbingan oleh pengawas sekolah binaan melalui bimbingan kelompok JARI DIVA. Permasalahan kemudian dirumuskan sebagai berikut: "Bagaimananakan Penerapan Bimbingan Kelompok JARI DIVA untuk Meningkatkan Kemampuan Guru dalam Mengembangkan PTS Berbasis Tema?" Selanjutnya, tujuan penulisan karya ilmiah ini secara umum untuk mendeskripsikan gagasan mengenai penerapan Bimbingan Kelompok JARI DIVA untuk meningkatkan kemampuan guru dalam mengembangkan PTS berbasis tema. Secara khusus mendeskripsikan tentang: (1) Strategi pelaksanaan bimbingan kelompok JARI DIVA untuk meningkatkan kemampuan guru mengembangkan PTS berbasis tema dan (2) Peningkatan kemampuan guru dalam mengembangkan PTS berbasis teme melalui bimbingan kelompok JARI DIVA.

Penulisan karya ilmiah ini diharapkan bermanfaat terutama bagi: pertama, memungkinkan peserta didik memperoleh layanan pembelajaran yang kondusif, efektif dan efisien serta peningkatan kualitas pembelajaran seiring peningkatan kompetensi guru dalam pengelolaan pembelajaran, dan supervisi akademik oleh kepala sekolah; kedua, memberikan peluang kepada guru dalam meningkatkan kemampuan pengelolaan pembelajaran melalui bimbingan kelompok JARI DIVA dan meningkatkan kualitas pengelolaan pembelajaran melalui layanan supervisi akademik terutama dalam pelaksanan penilaian pembelajaran; ketiga, menjadi pertimbangan kepala sekolah dalam melakukan layanan supervisi akademik terhadap guru terutama dalam pelaksanaan penilaian pembelajaran baik penilaian sikap, keterampilan maupun pengetahuan; dan keempat, memberikan peluang kepada pengawas sekolah memiliki guru dan kepala sekolah binaan yang kompeten terutama dalam pengelolaan pembelajaran dan supervisi akademik yang pada akhirnya 
berdampak pada peningkatan kualitas hasil belajar peserta didik.

\section{METODE}

Bimbingan kelompok JARI DIVA dilaksanakan pada semua sekolah binaan yang berjumlah 12 sekolah yang terbagi dalam tiga gugus yaitu gugus 13,16 , dan 19 Singkawang. Gugus 13 dan 16 Singkawang terletak di Kecamatan Singkawang Timur dan Gugus 19
Singkawang di Kecamatan Singkawang Utara. Fokus materi bimbingan mengenai pengembangan PTS berbasis tema. Bimbingan dilaksanakan terhadap guru kelas sasaran pelaksana kurikulum 2013 di kelas 1, 2, 4 dan 5 SD pada semester II Tahun Pelajaran 2017/2018 dan semester II tahun pelajaran 2018/2019. Peserta bimbingan sebagaimana tertera tabel berikut.

Tabel 1. Peserta Bimbingan Kelompok JARI DIVA untuk Meningkatkan Kemampuan Guru Mengembangkan PTS Berbasis Tema

\begin{tabular}{|c|c|c|c|c|}
\hline No & Gugus Sekolah & Waktu Pelaksanaan & $\begin{array}{l}\text { Jumlah } \\
\text { Sekolah }\end{array}$ & Jumlah Guru \\
\hline 1. & Gugus 19 Singkawang & Semester II 2017/2018 & 4 & 25 orang \\
\hline 2. & Gugus 13 Singkawang & Semester II 2018/2019 & 4 & 16 orang \\
\hline 3. & Gugus 16 Singkawang & Semester II 2018/2019 & 4 & 18 orang \\
\hline \multicolumn{3}{|c|}{ Jumlah } & 12 & 78 orang \\
\hline
\end{tabular}

Prosedur pemecahan masalah dilaksanakan melalui bimbingan kelompok JARI DIVA dilaksanakan melalui empat tahapan yaitu: tahap pertama, workshop penguatan konsep pengembangan PTS berbasis tema; tahap kedua, praktik pengembangan PTS berbasis tema melalui kerja kelompok dalam workshop sesuai kelompok kelas masing-masing. Setiap peserta diberikan tugas mengembangkan satu paket soal PTS tema tertentu yang dilaksanakan melalui kerja mandiri di tempat tugas masing-masing. Pengembangan PTS berbasis tema dalam kerja mandiri dilaksanakan sesuai dengan konsep pengembangan PTS berbasis tema yang diperkuat dalam workshop.

Tahapan ketiga, hasil kerja kelompok selanjutnya didiskusikan dalam kelompok kelas masing-masing untuk menyesuaiakan paket soal PTS berbasis tema antar peserta pada tema yang sama. Tahapan terakhir, hasil kerja akhir setiap kelas yang sudah disempurnakan berdasarkan hasil diskusi dilakukan validasi oleh pengawas sekolah untuk menentukan kesesuaian prosedur pengembangan PTS berbasis tema dan kesesuaian pengembangan soal dengan kisi-kisi PTS berbasis tema. Selanjutnya guru melakukan finalisasi Soal PTS berbasis tema yang sudah divalidasi pengawas sekolah sebelum digunakan guru kelas dalam pelaksanaan PTS di kelas masing-masing.

Alur pelaksanaan Bimbingan Kelompok JARI DIVA digambarkan diagram berikut.

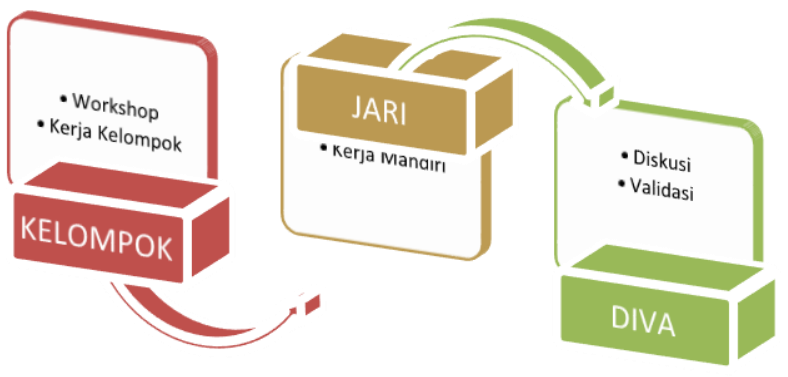

Gambar 1. Alur Pelaksanaan Bimbingan Kelompok 
Berdasarkan diagram di atas, bimbingan kelompok JARI DIVA dilaksanakan dalam tiga tahapan yaitu: tahapan pertama Bimbingan Kelompok melalui workshop dan kerja kelompok dalam pengembangan PTS berbasis tema, tahapan kedua dilaksanakan kerja mandiri (JARI) sebagai implementasi hasil workshop, dan tahapan ketiga dilaksanakan diskusi hasik kerja mandiri dan validasi hasil kerja mandiri dan diskudi oleh pengawas sekolah (DIVA). Hasil validasi yang dilakukan pengawas sekolah menjadi dasar bagi guru kelas untuk melakukan finalisasi soal PTS berbasis tema sebelum digunakan dalam pelaksanaan PTS di kelas masing-masing.

Data hasil pelaksanaan bimbingan kelompok JARI DIVA berupa hasil kerja peserta sesuai langkah-langkah pengembangan PTS berbasis tema. Instrumen yang digunakan dalam bimbingan kelompok JARI DIVA terdiri dari dua bagian yaitu: instrumen pengembangan PTS berbasis tema dan instrumen validasi pengembangan soal PTS berbasis tema. Instrumen pengembangan PTS terdiri dari format identifikasi muatan pelajaran dalam satu semester, pemetaan KD setiap tema dan sub tema, distribusi soal setiap KD muatan pelajaran, Kisi-Kisi Soal PTS berbasis tema dan soal PTS berbasis tema. Instrumen validasi pengembangan PTS berbasis tema memuat aspek kesesuaian prosedur pengembangan PTS berbasis tema dan kesesuaian soal tes dengan kisi-kisi PTS berbasis tema.

Teknik pengumpulan data yang digunakan adalah lembar ceklis pemenuhan hasil kerja setiap langkah pengembangan PTS berbasis tema dan rubrik penilaian kisi dan soal PTS berbasis tema. Selanjutnya hasil penilaian diolah menggunakan persentase hasil perbandingan skor capaian setiap kelompok kelas dengan skor ideal yang diharapkan pada setiap kriteria target hasil kerja.

\section{HASIL DAN PEMBAHASAN}

Bimbingan Kelompok JARI DIVA untuk meningkatkan kemampuan guru mengembangkan PTS berbasis tema dilaksanakan sejak semester tahun pelajaran 2017/2018 hingga pada semester II tahun pelajaran 2018/2019 pada gugus binaan yang berbeda. Pembimbingan dilaksanakan secara bertahap sesuai langkah-langkah pengembangan PTS berbasis tema sebagai mana digambarkan dalam gambar berikut.

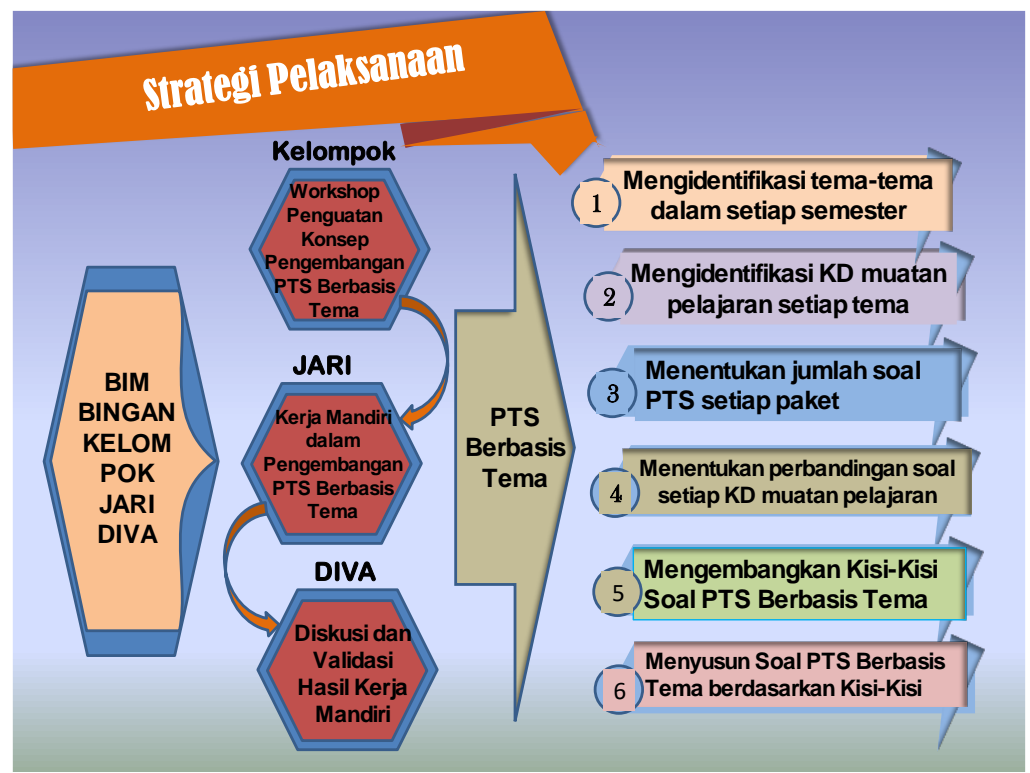

Gambar 2. Strategi Pelaksanaan Bimbinngan Kelompok JARI DIVA Dalam Pengambangan PTS Berbasis Tema 
Bimbingan Kelompok JARI DIVA untuk meningkatkan kemampuan guru dalam mengembangkan PTS berbasis tema pada gugus sekolah binaan diuraikan sebagai berikuti.

\section{Penguatan Konsep Pengembangan PTS Berbasis Tema}

Kegiatan bimbingan kelompok JARI DIVA dilaksanakan berdasarkan gugus sekolah binaan sejak semester II tahun pelajaran 2017/2018 di Gugus 19 Singkawang kemudian gugus 13 dan 16 pada semester II tahun pelajaran 2018/2019. Kegiatan pertama dalam bimbingan kelompok JARI DIVA adalah workshop peningkatan kemampuan guru dalam mengembangkan PTS Berbasis Tema dilaksanakan selama 2 (dua) hari, Gugus 19 dilaksanakan tanggal 25 dan 27 Januari 2018, Gugus 13 dilaksanakan tanggal 20-21 Februari 2019 dan Gugus 16 dilaksanakan pada tanggal 4-5 Maret 2019. Materi kegiatan workshop meliputi: pemetaan $\mathrm{KD}$ berdasarkan tema dan sub tema, langkahlangkah pengembangan kisi-kisi dan soal tes PTS berbasis tema. Kegiatan kedua, untuk memperkuat pemahaman konsep, peserta bimbingan melakukan kerja kelompok untuk melakukan pemetaan $\mathrm{KD}$, pengembangan kisi-kisi dan menyusun soal tes berdasarkan kisi-kisi.

Pemahaman yang diperoleh peserta bimbingan dalam workshop dilanjutkan dengan menyelesaikan tugas mandiri yang dibagi dalam kelompok kelas 1,2,4,dan 5 dengan durasi waktu satu minggu. Hasil kerja mandiri kemudian didiskusikan dalam kelompok kelas masing-masing kemudian dibahas dalam kelompok kelas agar setiap peserta bimbingan dapat berbagi pengalaman. Hasil diskusi kelompok dan kelas, setiap peserta melakukan finalisasi hasil kerja sehingga menjadi produk kisi-kisi dan soal tes yang akan digunakan dalam PTS berbasis tema yang wajib diserahkan kepada pengawas dalam bentuk file.

\section{Kerja Mandiri dalam Pengembangan PTS Berbasis Tema}

Kerja mandiri merupakan kelanjutan tugas yang sudah dibagi pada akhir workshop berdasarkan kelompok kelas yang diampu. Pemenuhan tugas bimbingan yang harus diselesaikan melalui kerja mandiri mengacu pada langkah-langkah-langkah pengembeangan Soal Tes berbasis tema. engembangan soal tes PTS berbasis tema dilaksanakan dengan prosedur langkahlangkah berikut:

a. Menentukan tema-tema dalam setiap semester

Langkah ini untuk menentukan jumlah paket soal PTS yang harus dibuat, hasil kerja seperti contoh berikut.

Tabel 2. Identifikasi Tema dalam Setiap Tingkat Kelas

\begin{tabular}{cccccc}
\hline \multirow{2}{*}{ Kelas } & \multirow{2}{*}{ Jumlah } & Tema & Semester 1 & \multicolumn{3}{c}{ Semester 2 } \\
\cline { 3 - 6 } & & PTS & PAS & PTS & PAT \\
\hline I & 8 & T 1 dan 2 & T 1 s.d. T 4 & T 5 dan 6 & T 5, 6,7,dan 8 \\
\hline II & 8 & T 1 dan 2 & T 1 s.d. T 4 & T 5 dan 6 & T 5, 6,7,dan 8 \\
\hline IV & 9 & T 1, 2, dan 3 & T 1 s.d. T 5 & T 6 dan 7 & T 5, 6,7,dan 8 \\
\hline V & 9 & T 1, 2, dan 3 & T 1 s.d. T 5 & T 6 dan 7 & T 5, 6,7,dan 8 \\
\hline
\end{tabular}


Melalui tabel di atas, dapat diketahui lingkup materi PTS di kelas I dan II adalah tema 1 dan 2 pada semester I dan tema 5 dan 6 pada semester II, sedangkan kelas IV dan $\mathrm{V}$ semester I tema 1,2, dan 3, semester II tema 6 dan 7. b. Mengidentifikasi KD muatan pelajaran setiap tema yang sudah ditentukan Langkah kedua ini bertujuan untuk mengetahui Kompetensi dasar yang muncul dalam pembelajaran setiap sub tema dalam satu tema. Informasi ini bermanfaat untuk menentukan proporsi soal PTS pada setiap muatan pelajaran.

Tabel 3. Identifikasi KD Muatan Pelajaran pada Setiap Tema

\begin{tabular}{lccccccc}
\hline \multirow{2}{*}{ Kelas } & \multirow{2}{*}{ Smtr } & \multicolumn{5}{c}{ Muatan Pelajaran } \\
\cline { 3 - 7 } & & PPKn & \multicolumn{1}{c}{ B.Ind } & MTK & SBdP & PJOK \\
\hline I & I & $3.2(3)$ & $3.1 ., 3.2$, & $3.1,3.2$, & $3.1,3.2$, & 3.3, & 3.4, \\
& & $3.3(1)$ & $3,3,3,4,3,9,3,11$ & $3.3,3.4$ & $3.3,3.4$ & 3.8 & \\
\hline dst & & & & & &
\end{tabular}

c. Langkah ketiga, menentukan jumlah soal PTS yang akan dibuat.

Kegiatan ini berguna untuk menentukan perbandingan jumlah soal yang dapat dikembangkan pada kompetensi dasar muatan pelajaran tertentu dalam satu paket soal PTS.

\section{Contoh: Tema 1 di Kelas I dan II dibagi} menjadi dua paket yaitu:

Paket 1 terdiri dari muatan pelajaran PPKn dan Bahasa Indonesia sejumlah 15 soal.
Paket 2 terdiri dari mauatan pelajaran MATEMATIKA, SBdP, PJOK) sejumlah 20 soal

d. Menentukan perbandingan soal pada setiap KD muatan pelajaran.

Langkah keempat ini bertujuan untuk menentukan perbandingan jumlah soal pada KD tertentu pada muatan pelajaran sesuai proporsi yang sudah ditentukan.

Tabel 4. Menentukan Perbandingan Soal antar KD Muatan Pelajaran

\begin{tabular}{|c|c|c|c|c|c|c|}
\hline \multirow{3}{*}{ Kelas } & \multirow{3}{*}{ Smtr } & \multicolumn{5}{|c|}{ Muatan Pelajaran } \\
\hline & & \multicolumn{2}{|c|}{ Paket 1} & \multicolumn{3}{|c|}{ Paket 2} \\
\hline & & PPKn & B.Ind & MTK & SBdP & PJOK \\
\hline \multirow{2}{*}{ I } & 1 & 6 & 9 & 10 & 5 & 5 \\
\hline & 2 & 6 & 9 & 10 & 5 & 5 \\
\hline
\end{tabular}

e. Mengembangkan Kisi-Kisi Soal PTS Berbasis Tema Langkah kelima ini, peserta dapat mengembangkan kisi-kisi soal PTS berbasis tema dengan memperhatikan KD setiap mupel pada paket soal tertentu. Sebelumnya ditentukan indikator pada KD mupel yang akan dibuat soal paket tertentu.

Tabel 5. Contoh Kisi-Kisi Soal PTS Berbasis Tema

\begin{tabular}{|c|c|c|c|c|c|}
\hline Mupel & $\begin{array}{l}\text { Kompetensi } \\
\text { Dasar }\end{array}$ & Indikator & Indikator Soal & $\begin{array}{l}\text { Tahapan Bentuk } \\
\text { Berpikir Soal }\end{array}$ & $\begin{array}{l}\text { No. } \\
\text { Soal }\end{array}$ \\
\hline PPKn & $\begin{array}{l}\text { Mengidentifikasi } \\
\text { aturan yang } \\
\text { berlaku dalam }\end{array}$ & $\begin{array}{l}\text { Mengidentifi } \\
\text { kasi aturan } \\
\text { yang berlaku }\end{array}$ & $\begin{array}{l}\text { Disajikan } \\
\text { wacana, siswa } \\
\text { mampu }\end{array}$ & Isian & 1 \\
\hline
\end{tabular}




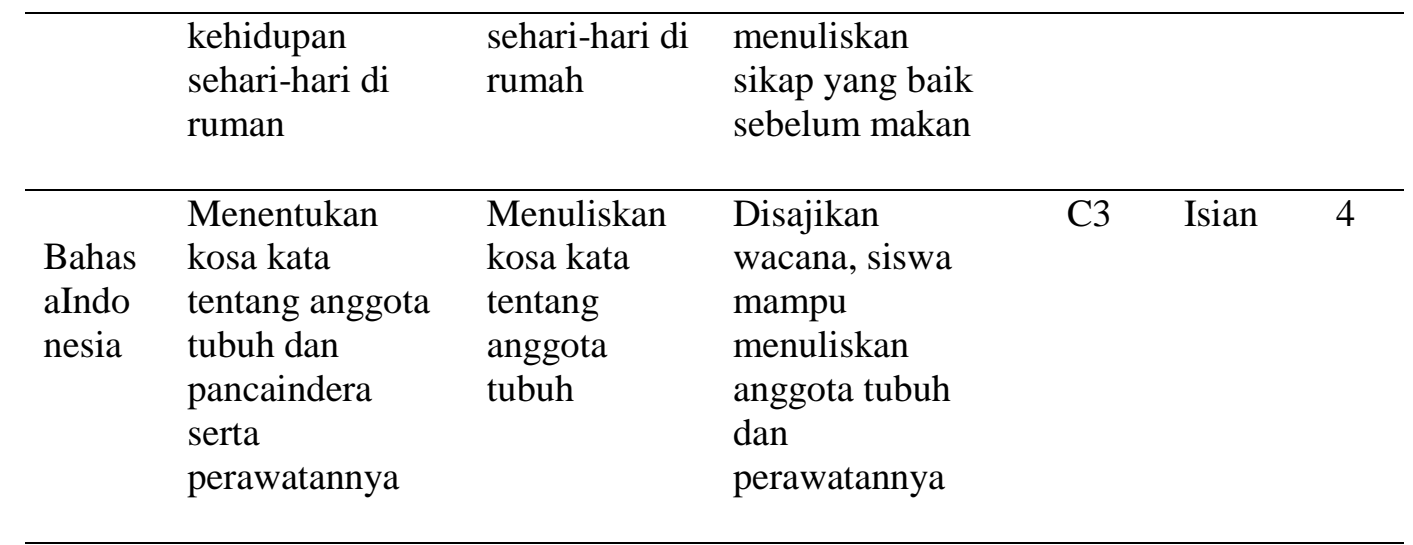

dst

f. Menyusun Soal PTS berdasarkan Kisi-Kisi Langkah keenam merupakan langkah terakhir dalam pengembangan PTS berbasis tema. Soal yang dirumuskan tetap memperhatikan kisi-kisi PTS yang ditetapkan sebekumnya

Langkah keenam di atas merupakan langkah terakhir dalam pengembangan soal PTS berbasis tema dan merupakan naskah soal yang dapat digunakan oleh guru dalam pelaksanaan PTS di kelas masing-masing

\section{Diskusi dan Validasi Hasil Kerja}

Tahapan Bimbingan Kelompok JARI DIVA berikutnya adalah diskusi dan berbagi hasil kerja mandiri dalam kelompok kelas masing-masing agar setiap peserta dapat menyesuaikan hasil kerjanya dengan peserta lain yang menyusun kisi dan soal pada tema tertentu. Selanjutnya hasil diskusi dilakukan validasi oleh pengawas sesuai kriteria dan panduan penyusunan PTS berbasis tema. Hasil Valaidasi menjadi bahan untuk menyempurnakan hasil kerja mandiri
Contoh:

Indikator soal : disajikan wacana, peserta didik dapat menentukan sikap yang baik sebelum makan

sehingga dihasilkan produk soal PTS yang sesuai dan dapat digunakan dalam pelaksanaan PTS di kelas atau sekolah masing-masing.

\section{Hasil Bimbingan Kelompok JARI DIVA}

Produk akhir yang dihasilkan dalam bimbingan kelompok JARI DIVA adalah naskah soal PTS yang terdiri dari beberapa muatan pelajaran pada yang dibelajarkan. Pelaksanaan bimbingan yang dilaksanakan terhadap guru pelaksana kurikulum 2013 di Gugus 13, 16, dan 19 ternyata mampu meningkatkan kemampuan guru menyusun kisi-kisi dan soal PTS berbasis tema sebagaimana digambarkan tabel berikut.

Tabel 6. Hasil Pengembangan PTS Berbasis Tema Melalui Bimbingan Kelompok JARI DIVA

\begin{tabular}{|c|c|c|c|c|c|c|}
\hline \multirow{2}{*}{ No } & \multirow{2}{*}{ Sekolah } & \multicolumn{4}{|c|}{ Kelas } & \multirow{2}{*}{ Persentase } \\
\hline & & I & II & IV & $\mathrm{V}$ & \\
\hline 1 & SDN 84 Singkawang & 2 & 2 & 1 & 2 & 87,50 \\
\hline 2 & SDN 89 Singkawang & 2 & 1 & 1 & 1 & 83,33 \\
\hline 3 & SDN 93 Singkawang & 1 & 1 & 1 & 1 & 80,00 \\
\hline 4 & SDN 94 Singkawang & 1 & 2 & 1 & 1 & 83,33 \\
\hline \multicolumn{2}{|c|}{ Persentase Gugus 19 Skw } & 85,71 & 75 & 80 & 75 & 84,00 \\
\hline
\end{tabular}




\begin{tabular}{ccccccc}
\hline 5 & SDN 61 Singkawang & 1 & 1 & 1 & 1 & 100 \\
\hline 6 & SDN 67 Singkawang & 1 & 1 & 1 & 0 & 75,00 \\
\hline 7 & SDN 68 Singkawang & 1 & 1 & 0 & 1 & 75,00 \\
\hline 8 & SDN 71 Singkawang & 1 & 1 & 1 & 1 & 100 \\
\hline \multicolumn{2}{c}{ Persentase Gugus 13 Skw } & 100 & 100 & 75 & 75 & 87,50 \\
\hline 9 & SDN 69 Singkawang & 1 & 1 & 1 & 1 & 80,00 \\
\hline 10 & SDN 70 Singkawang & 1 & 1 & 1 & 1 & 80,00 \\
\hline 11 & SDN 72 Singkawang & 1 & 1 & 1 & 1 & 100 \\
\hline 12 & SDN 74 Singkawang & 1 & 1 & 1 & 1 & 75,00 \\
\hline \multicolumn{2}{l}{ Persentase Gugus 16 Skw } & 80 & 80 & 100 & 75 & 83,75 \\
\hline \multicolumn{2}{l}{ Rata-Rata } & 88,57 & 85 & 85 & 75 & 85,08 \\
\hline
\end{tabular}

Berdasarkan tabel di atas menunjukan kemampuan guru dalam mengembangkan PTS berbasis tema ditunjukan oleh produk kisi-kisi dan soal PTS yang dikumpulkan dan digunakan dalam pelaksanaan PTS semester II tahun pelajaran 2017/2018 di Gugus 19 Singkawang sejumlah $84 \%$ dan semester II tahun pelajaran 2018/2019 di Gugus 13 sejumlah 87,50\% dan Gugus 16 Singkawang sejumlah $83,75 \%$. Selanjutnya pada kelompok sekolah diperoleh $80 \%$ untuk kelas I dan II, $100 \%$ untuk kelas IV dan $75 \%$ untuk kelas V.
Hasil kerja peserta bimbingan kelompok JARI DIVA dilakukan validasi kesesuaian prosedur pengembangan PTS berbasis tema dengan kriteria: ketersediaan pemetaan KD pertema (I), kesesuaian distribusi soal setiap KD mupel (II), kesesuaian proporsional sebaran soal setiap KD mupel (III), kesesuaian Kisi-Kisi dengan distribusi dan pemetaan KD mupel (IV), kesesuaian bentuk soal dengan kisi-kisi dan tingkat kelas $(\mathrm{V})$, kelengkapan perangkat soal PTS (VI) diperoleh hasil sebagai berikut:

Tabel 7. Hasil Validasi Pengembangan PTS Berbasis Tema Melalui Bimbingan Kelompok JARI DIVA

\begin{tabular}{ccccccc}
\hline \multirow{2}{*}{ No } & \multirow{2}{*}{ Gugus Sekolah } & \multicolumn{4}{c}{ Kelas } & \multirow{2}{*}{ Rata-Rata } \\
\cline { 2 - 5 } & Gugus 13 Singkawang & 87,50 & II & IV & V & \\
\hline 1 & Gu,58 & 91,67 & 75,00 & 85,94 \\
\hline 2 & Gugus 16 Singkawang & 95,83 & 75,00 & 91,67 & 75,00 & 84,38 \\
\hline 3 & Gugus 19 Singkawang & 85,42 & 95,83 & 89,58 & 81,25 & 88,02 \\
\hline \multicolumn{2}{c}{ Rata-Rata } & 89,58 & 86,80 & 90,97 & 77,08 & 86,11 \\
\hline
\end{tabular}

\section{Pembahasan}

Permasalahan yang bersifat kelompok menjadi prioritas untuk segera diatasi melalui permbimbingan pengawas sekolah secara kelompok dengan harapan akan memberikan dampak lebih luas terhadap peningkatan proses penyelenggaraan pembelajaran dan sekolah. Pelaksanaan PTS pada sekolah pelaksana kurikulum 2013 yang masih dilaksanakan secara parsial berdasarkan muatan pelajaran menimbulkan kesulitan bagi peserta didik untuk menyiapkan diri mengikuti penilaian tengah semester. Kemampuan guru yang rendah dalam mengembangkan PTS berbasis tema memerlukan layanan pengawas sekolah. Bimbingan kelompok JARI DIVA menjadi alternatif untuk meningkatkan kemampuan guru mengembangkan PTS berbasis tema di gugus 13, 16, dan 19 Singkawang.

Bimbingan Kelompok JARI DIVA yang diawali dengan pelaksanaan workshop penguatan konsep pengembangan PTS berbasis tema dan diperkuat dengan latihan dalam kerja kelompok, kemudian dilanjutkan dengan kerja mandiri mempraktikkan konsep pengembangan PTS berbasis tema yang diperoleh melalui workshop. Kerja mandiri yang dilakukan guru mengacu pada langkahlangkah pengembangan PTS berbasis tema 
sebagai berikut: (1) Mengidentifikasi tematema yang terdapat pada kelas-kelas tertentu untuk menentukan lingkup materi PTS yang akan dikembangkan, (2) Menganalisis Kompetensi Dasar setiap muatan pelajaran yang dibelajarkan pada tema, (3) Menentukan jumlah soal PTS yang akan dibuat pada setiap paket soal PTS, (4) Menentukan perbandingan jumlah soal setiap Kompetensi Dasar muatan pelajaran pada satu paket soal, (5) Mengembangkan kisi-kisi soal PTS sesuai indikator Kompetensi Dasar muatan pelajaran, dan (6) Mengembangkan soal PTS berdasarkan kisi-kisi yang sudah dirumuskan. Bimbingan kelompok JARI DIVA untuk meningkatkan kemampuan guru mengembangkan PTS berbasis tema yang dilaksanakan pada semester II tahun pelajaran 2017/2018 di Gugus 19 Singkawang dan semester II tahun pelajaran 2018/2019 di Gugus 13 dan 16 Singkawang diperoleh hasil sebagaimana digambarkan pada gambar berikut.

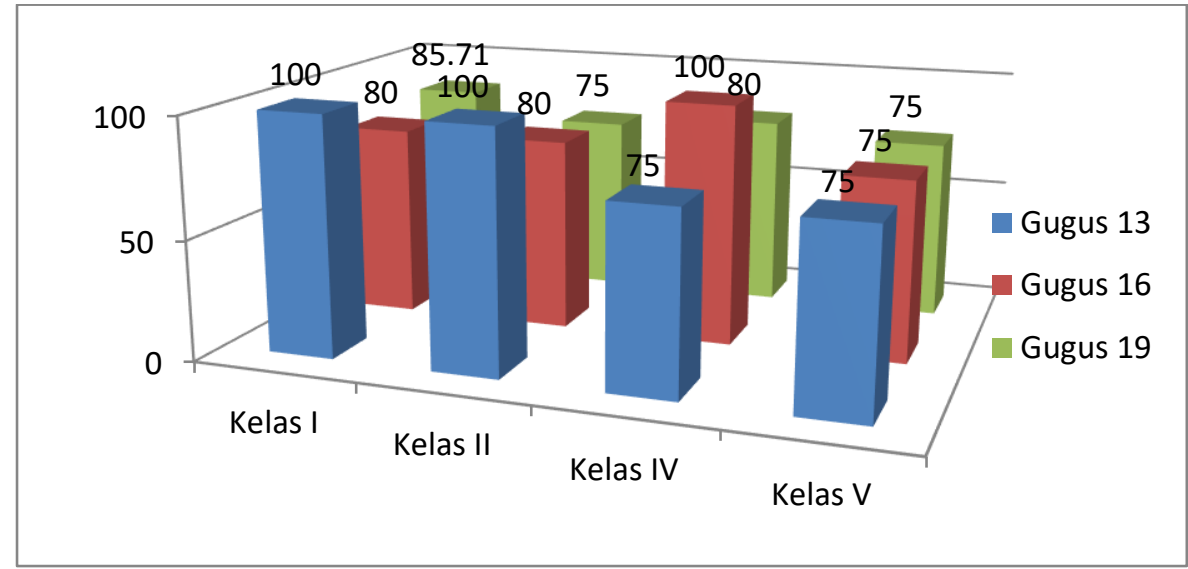

\section{Gambar 4. Capaian Target Pengembangan PTS Berbasis Tema Melalui Bimbingan Kelompok JARI DIVA}

Berdasarkan diagram di atas, peserta mampu menyelesaikan target bimbingan kelompok JARI DIVA yaitu Kisi-Kisi dan Soal PTS Berbasis Tema bervariasi antara $75 \%$ sampai $100 \%$. Selanjutnya dilakukan validasi terhadap hasil kerja peserta bimbingan kelompok JARI DIVA dengan memperhatikan pemenuhan kriteria pemenuhan hasil kerja setiap langkah pengembangan PTS berbasis tema, kesesuaian indikator soal dengan indikator kompetensi dasar, kesesuaian soal tes dengan indikator soal dan kelengkapan kunci jawab dan pedoman penskoran. Hasil validasi sebagaimana digambarkan pada gambar berikut. 


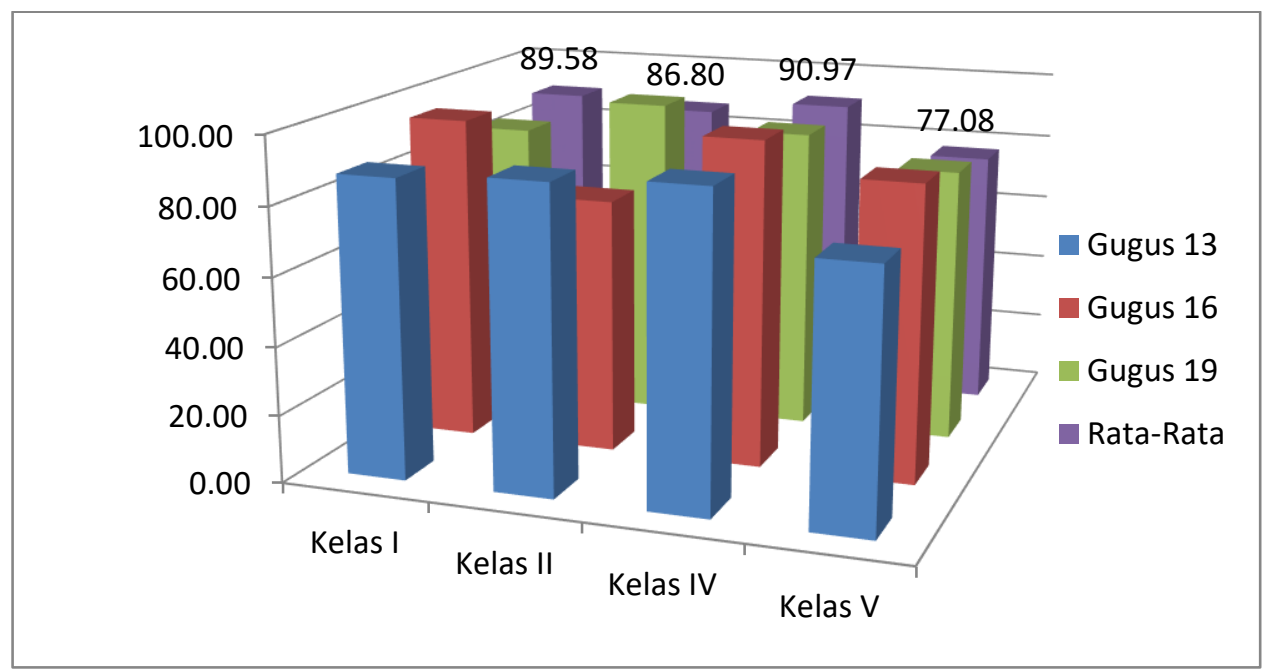

\section{Gambar 5. Hasil Validasi Pengembangan PTS Berbasis Tema Melalui Bimbingan Kelompok JARI DIVA}

Berdasarkan diagram di atas memberikan pemahaman bahwa Bimbingan Kelompok JARI DIVA dapat meningkatkan kemampuan guru dalam mengembangkan PTS berbasis tema, kelas I dengan capaian $89,58 \%$, kelas II dengan capaian $86,80 \%$, kelas IV dengan capaian 90,97\%, dan kelas V dengan capaian 77,08. Bimbingan Kelompok JARI DIVA yang diawali dengan workshop penguatan konsep sesuai materi bimbingan, dilanjutkan kerja mandiri dan diskusi dalam kelompok hasil kerja mandiri, kemudian dilanjutkan dengan validasi hasil kerja mandiri memungkinkan guru memiliki kemampuan dalam mengembangkan PTS berbasis tema.

\section{SIMPULAN DAN SARAN \\ Simpulan}

Berdasarkan paparan pada pelaksanaan bimbingan Kelompok JARI DIVA dan pembahasan dapat disimpulkan sebagai berikut: (1) Bimbingan Kelompok JARI DIVA dilaksanakan melalui workshop dilanjutkan kerja mandiri, diskusi kelompok dan validasi pengawas, kemudian finalisasi hasil kerja mandiri berdasarkan hasil diskusi kelompok dan validasi, (2) Bimbingan Kelompok JARI DIVA dapat digunakan untuk meningkatkan kemampuan guru dalam mengembangkan kisi-kisi dan soal PTS Berbasis Tema.

\section{Saran}

Merujuk pada pernyataan dalam hasil penelitian, pembahasan dan simpulan disarankan sebagai berikut: (1) Diharapkan setiap peserta bimbingan kelompok pada masa berikutnya tetap komitmen dengan program dan jadwal bimbingan, dan (2) Diharapkan partisipasi pembina guru dan kepala sekolah untuk mengarahkan guru dan kepala sekolah melakukan pengembangan diri melalui bimbingan kelompok.

\section{DAFTAR PUSTAKA}

Arifin, Zaenal. (2009). Evaluasi Pembelajaran Prinsip Teknik Prosedur. Bandung: Remaja Rosdakarya.

Harsiati,Titik dan Imam Agus Basuki. (2012). Pemberdayaan Guru Sekolah Dasar Penilaian Berbasis Kelas. Malang: TEQIP

Kunandar. (2013). Penilaian Autentik (Penilaian Hasil Belajar Peserta Didik Kurikulum 2013) Suatu Pendekatan Praktis. Jakarta:Raja Grafindo Persada

Kemdikbud. (2012). Supervisi Akademik Bahan Ajar Diklat Supervisi Pengawas Sekolah, Jakarta: Pusbangtendik BPSDMP\&K dan PMP Depdikbud 
Kemdikbud. (2014). Supervisi Akademik Implementasi Kurikulum 2013, Bahan Ajar Implementasi Kurikulum 2013 untuk Pengawas Sekolah, Jakarta: Pusbangtendik BPSDMP\&K dan PMP Kemdikbud.

Kemdikbud. (2016). Panduan Penilaian untuk Sekolah Dasar (SD). Jakarta: Direktorat Pembinaan SD Dirjen Dikdasmen

Rahman,Asfah, Ilzam Marzuk dan Zainal. (2016). Modul Pengawas Sekolah Pembelajar Kelompok Kompetensi B Konsep Supervisi Manajerial,
Jakarta: Direktorat Jenderal Guru dan Tenaga Kependidikan Kementerian Pendidikan dan Kebudayaan

Sagala, Syaiful. (2012). Supervisi Pembelajaran dalam Profesi Pendidikan. Bandung:Alfabeta

Siahaan,Amiruddin, Rambe Asli dan Mahidin. (2006). Manajemen Pengawas Pendidikan, Strategi Efektif Aplikasi Konsep Kesupervisian Menuju Pencapaian Tujuan Pendidikan Bermutu. Jakarta:Quantum Teaching. 